\title{
Experiência de Gamificação na Organização dos Trabalhos de Conclusão de um Curso Técnico em Informática
}

\author{
Gian Luca Motta Flores ${ }^{1}$, Ângelo Nery Vieira Crestani ${ }^{1}$, Rudieri Dietrich Bauer ${ }^{1}$, \\ Jaline Gonçalves Mombach ${ }^{1}$ \\ ${ }^{1}$ Instituto Federal de Educação, Ciência e Tecnologia Farroupilha \\ RS-377, Km 27 - Passo Novo - CEP 97555-000 - Alegrete - RS \\ \{gianlucamottaflores, angelovieira.c, rudierib\}@gmail.com \\ jaline.mombacheiffarroupilha.edu.br
}

\begin{abstract}
Students of Integrated Technical Course in Informatics (medium level), most teenagers, have difficulty to comply and organize their final works. Therefore, this paper describes the experience of the gamification approach using the Class Dojo platform. The results indicate that methodology is viable and can be replicated in other educational institutions.
\end{abstract}

Resumo. Alunos de Curso Técnico em Informática Integrado, maioria adolescentes, têm dificuldade para cumprir e organizar seus trabalhos finais. Assim, este artigo descreve a experiência obtida a partir de uma abordagem de gamificação usando a plataforma Class Dojo. Os resultados indicam que a metodologia é viável e pode ser replicada em outras instituições de ensino.

\section{Introdução}

O uso de jogos como recurso de ensino não é necessariamente algo inovador, porém um novo termo tem sido discutido de forma progressiva: "gamificação". Conforme Kapp (2012), os jogos digitais são excelentes ambientes de aprendizagem, principalmente porque permitem a falha, o tentar novamente, o senso de controle e a colaboração entre pares. Dessa forma, gamificação é a aplicação de técnicas e metodologias de jogos digitais em diferentes contextos.

Gee (2003) descreve que a gamificação aplicada na educação gera motivação nos estudantes, que criam prioridades para atingir os objetivos propostos. A aplicação de um ambiente gamificado no ensino resulta em benefícios, como o compartilhamento de conhecimentos, experiência em grupo e uma melhor preparação para o mercado de trabalho, devido aos objetivos que precisam ser alcançados.

No Instituto Federal de Educação, Ciência e Tecnologia Farroupilha, Campus Alegrete, percebeu-se que os alunos do último ano do curso Técnico em Informática Integrado, isolavam-se durante a realização do Trabalho de Conclusão de Curso (TCC). Além disso, a maioria dos discentes deste nível de ensino são adolescentes e relatam dificuldade para organização e cumprimento do cronograma de orientação. A desmotivação em alguns alunos era evidente e ao final do ano letivo um número expressivo de alunos ficava em recuperação no TCC.

Diante deste contexto, o principal objetivo deste trabalho é relatar a experiência obtida com uma metodologia baseada em gamificação para organização dos TCCs do em um Curso Técnico em Informática Integrado. 


\section{Gamificação na Educação}

Gamificação pode ser considerada a aplicação de jogos apropriados para resolução de problemas e incentivo à aprendizagem e tem por meta aumentar a motivação e engajamento, trabalhando quesitos como cooperativismo, competitividade, entre outras questões que devem ser melhoradas, dependendo da área em que é aplicado o método (MUNTEAN, 2011).

Essa metodologia como apoio à disciplinas escolares tem sido aplicada frequentemente. Exemplifica-se como trabalhos relacionados as abordagens de Iosup e Epema (2014) e Bitencourt (2014). Durante três anos de pesquisa em um projeto sobre a eficiência da gamificação na educação, Iosup e Epema (2014) trabalharam com aproximadamente 450 alunos. A partir da análise de resultados positivos e negativos durante o período de aplicação, os autores concluíram que a gamificação auxiliou principalmente no aumento da taxa de aprovação de estudantes, comparando com a porcentagem de reprovação anterior. Já Bitencourt (2014) relata a experiência obtida na gamificação de uma disciplina no Curso de Licenciatura em Computação em um Instituto Federal. Conforme o autor, um dos principais ganhos desta metodologia é a possibilidade de observar os diferentes ritmos de trabalho dos alunos, bem como acompanhamento pessoal do progresso de cada aluno, algo que não é facilitado em sistemas tradicionais de ensino.

Quanto às metodologias empregadas, os autores mencionam sistemas próprios para pontuação e níveis nas disciplinas. No entanto, Maclean-Blevins e Muilenburg (2013) descreve o uso de uma plataforma livre e que oferece diferentes recursos, o Class Dojo $^{1}$

\section{Relato de Experiência}

A turma de concluintes do Curso Técnico em Informática Integrado deve elaborar um trabalho de conclusão, que consiste no desenvolvimento de um sistema e/ou outra tarefa prática e na escrita de um artigo completo. Porém, a turma de 2016, formada por 15 estudantes, com idades entre 16 e 19 anos apresentou baixo rendimento no primeiro semestre e constatou-se que era necessário nova abordagem, visto que a turma anterior (2015) também teve dificuldades para organização individual do trabalho. Dessa forma, a metodologia adotada foi desenvolvida em quatro etapas:

1. Estudo do Contexto: dinâmica com os alunos e intervenção com o setor psicológico para traçar as dificuldades encontradas e as metas individuais.

2. Plataforma de Gamificação: configuração da plataforma para gamificação junto com os alunos

3. Acompanhamento: rotina semanal de acompanhamento das metas e desenvolvimento do TCC, bem como distribuição de pontuações

4. Avaliação: avaliação com a equipe e alunos para verificação de questões positivas e negativas da metodologia

Primeiramente, realizou-se uma dinâmica com os alunos para descobrir como a turma estava se sentindo com a realização do TCC. As questões abordadas foram: $O$ que eu quero apresentar no TCC? O que eu já fiz? O que falta fazer? Como eu me sinto? Quais as dificuldades? Do que eu preciso? . Após a dinâmica, verificou-se que muitos

\footnotetext{
${ }^{1}$ Class Dojo. Disponível em https://www.classdojo.com/pt-br/
} 
alunos sentiam-se desmotivados com os estudos e principalmente com as tarefas que precisavam ser realizadas no TCC. Nas dificuldades, observou-se que muitos não procuravam o professor orientador, não cumpriam o cronograma e alguns não ajudavam os colegas. Solicitou-se aos alunos que criassem metas individuais, necessárias para conclusão do trabalho. Logo, a segunda etapa foi a configuração da plataforma e acesso dos alunos.

A plataforma escolhida para trabalho foi Class Dojo, ferramenta que consiste em um sistema de avaliação comportamental on-line. Os comportamentos a serem pontuados são editados pelo professor e podem ser acompanhados por educandos e pais, se os mesmos realizarem o cadastro. Os pontos podem ser agregados positivamente ou negativamente e realizam um total para a turma, obtendo um montante da pontuação de todos os alunos. A Tabela 1 apresenta as habilidades configuradas para a turma.

\begin{tabular}{|c|c|c|c|}
\hline \multicolumn{2}{|c|}{ Habilidades Posititvas } & \multicolumn{2}{c|}{ Habilidades a Melhorar } \\
\hline Descrição & Pontuação & Descrição & Pontuação \\
\hline Ajudando os outros & 1 & Desatenção em aula & 0 \\
\hline Autonomia & 2 & Desrespeito aos colegas & -1 \\
\hline Cumprindo o cronograma & 4 & Não cumprindo o cronograma & -1 \\
\hline Foco na formatura & 1 & Não estudando & -1 \\
\hline Motivação & 2 & Não falando com o orientador & -1 \\
\hline Persistência & 2 & Realização de outras atividades & -3 \\
\hline Procurando o orientador & 3 & durante a disciplina de TCC & -2 \\
\hline Trabalho em aula & 4 & Plágio & -2 \\
\hline
\end{tabular}

Tabela 1. Habilidades configuradas para a turma

O acompanhamento da turma é semanal e a professora da disciplina registra a pontuação no sistema, conforme realização de atividades dos estudantes. O cronograma adotado foi criado pelos próprios alunos e são as metas individuais de cada um. Além disso, há comunicação direta com os orientadores dos alunos para verificar se eles estão procurando-os para orientação. A Figura 1 demonstra a visão do professor sobre a plataforma, sendo esta tela a apresentação da configuração da turma no Class Dojo, em que cada aluno configura seu personagem.

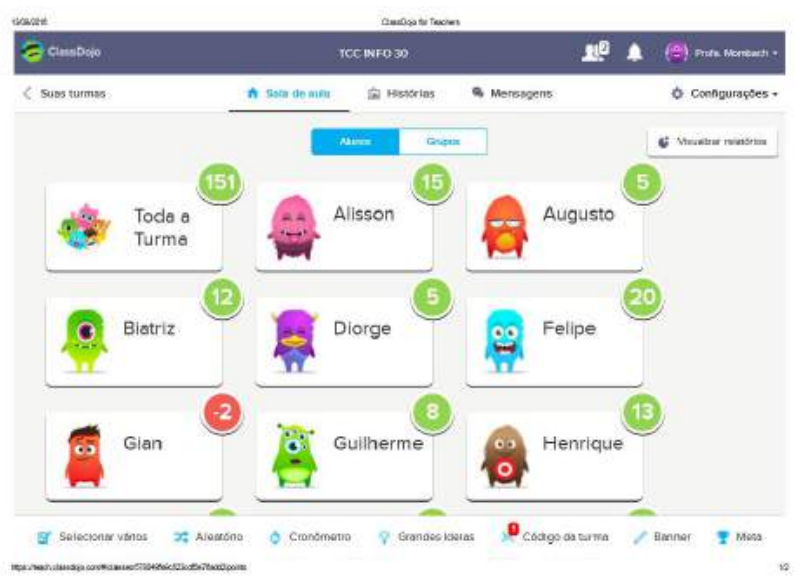

Figura 1. Alunos, respectivas pontuações e ambiente virtual 
O ambiente virtual apresentado ao discente difere da visão do docente, sendo possível visualizar apenas seus dados.

A participação dos responsáveis do estudante, apesar de viável pelo sistema e recomendada por educadores para acompanhamento das atividades do aluno, não foi numerosa. Apenas dois pais realizaram cadastro, apesar do envio das informações e realização de reunião com os responsáveis para anunciar a nova metodologia empregada.

\section{Considerações Finais}

Inicialmente, observou-se certa estranheza dos alunos com a plataforma, principalmente devido à aparência lúdica com personagens. Porém, todos os discentes demonstraram entusiasmo com as pontuações e com os desafios semanais propostos.

A plataforma possibilita análise de progresso dos alunos, facilitando o acompanhamento individual destes. Os alunos habituaram-se ao novo método avaliativo de seus comportamentos, e a maioria, passou a cumprir o seu cronograma de tarefas individuais do TCC, gerando pontos positivos para si e para a turma. Salienta-se também a aprendizagem colaborativa, pois quando um aluno não conseguia resolver algum erro em seu código, outros tentavam auxiliá-lo. Em contraponto, alguns alunos do grupo não mudaram seu comportamento, mesmo diante da nova metodologia. Dessa forma, quatro alunos reprovaram no TCC.

Percebe-se que a proposta é viável e que necessita de aplicação em outras turmas para resultados mais objetivos. Porém, a docente, que também ministrou a disciplina no ano anterior, relatou que percebeu mudança no comportamento dos alunos e a plataforma está sendo adotada novamente na turma de 2017.

\section{Referências}

BITENCOURT, R. B. Experiência de gamificação do ensino na licenciatura em computação no sertão pernambucano. XIII Simpósio Brasileiro de Games e Entretenimento Digital (SBGames 2014), 2014.

GEE, J. P. What video games have to teach us about learning and literacy. Computers in Entertainment (CIE), ACM, v. 1, n. 1, p. 20-20, 2003.

IOSUP, A.; EPEMA, D. An experience report on using gamification in technical higher education. In: ACM. Proceedings of the 45th ACM technical symposium on Computer science education. [S.1.], 2014. p. 27-32.

KAPP, K. M. The gamification of learning and instruction: game-based methods and strategies for training and education. [S.1.]: John Wiley \& Sons, 2012.

MACLEAN-BLEVINS, A.; MUILENBURG, L. Using class dojo to support student self-regulation. In: Proceedings of World Conference on Educational Multimedia, Hypermedia and Telecommunications. [S.1.: s.n.], 2013. p. 1684-1689.

MUNTEAN, C. I. Raising engagement in e-learning through gamification. In: Proc. 6th International Conference on Virtual Learning ICVL. [S.1.: s.n.], 2011. p. 323-329. 